\title{
Lattuada, Mario. (2021). La política agraria en tiempos de la grieta. Argentina (2003-2019). Teseo- Universidad Abierta Interamericana, Ciudad Autónoma de Buenos Aires, Primera edición, 302 páginas. ISBN 978-987-723-283-7.
}

RESEÑA DE LIBRO

\author{
Por María Agustina Arrién \\ Universidad Nacional de Quilmes. Contacto: agus.arrien@gmail.com
}

Recibido: agosto de 2021

Aceptado: septiembre de 2021

La cultura política argentina ha estado signada por fuertes antinomias desde los mismos inicios de la historia nacional, allá por las primeras décadas del siglo XIX: unitarios $\mathrm{y}$ federales primero, peronistas $\mathrm{y}$ antiperonistas en el siglo $\mathrm{XX}, \mathrm{y}$, en estos tiempos que corren, se encuentra vigente la antinomia kirchneristas y antikirchnernistas. Producto de esta última antinomia surge lo que se ha dado en llamar "la grieta", expresión utilizada para demarcar dos partes distintas de la sociedad argentina que están enfrentadas y se colocan cada una a ambos lados de la división. Si bien desde el ámbito de lo discursivo el análisis de la grieta puede arrojar resultados fructíferos, cuando se trata de trasladar el discurso polarizante a la práctica, con el ojo puesto en las políticas públicas sectoriales destinadas al sector agropecuario, la dinámica propia de las transformaciones del espacio rural argentino hace que esta arenga de la grieta pierda en poder dicotomizante y gane en relatividad y contradicción. Es en este sentido en que Lattuada dirige su investigación de las políticas públicas sectoriales para el agro argentino en el período 2003-2019, el cual abarca tres presidencias: Néstor Kirchner (2003-2007), Cristina Fernández de Kirchner (2007-2011 y 2011-2015), y Mauricio Macri (2015-2019). En la obra reseñada, el autor nota que allí donde en el discurso parece haber posiciones irreconciliables e insalvables, las tendencias estructurales en lo social y económico en el campo argentino continuaron desarrollándose sin mayores alteraciones a pesar de las distintas políticas llevadas a cabo. A lo largo de seis capítulos $^{1}$, Lattuada se propone lo siguiente: analizar la trama política, social y económica de la Argentina entre 2003 y 2019, y las políticas públicas destinadas al sector agropecuario que, en algunos casos por acción y otros por omisión, contribuyeron a construir una variable

\footnotetext{
${ }^{1}$ El capítulo primero alude a la administración pública sectorial y capacidades estatales; el segundo a la política de tierras; el tercero a las políticas para la agricultura familiar y el desarrollo rural; el cuarto a las políticas para la agricultura comercial exportadora; el quinto a los Resultados obtenidos a partir de las acciones e inacciones gubernamentales y el sexto refiere a las alianzas y conflictos desplegados en los distintos contextos partidarios.
} 
dicotómica, a partir de la que se caracterizó la denominada "grieta" y se fueron desplegando distintas relaciones sociales, alianzas y conflictos.

En el primer capítulo de la obra se abordan las formas de organización del Estado y las capacidades políticas y administrativas construidas para llevar adelante los respectivos proyectos, indagando tanto en el grado de institucionalización de estos, las contradicciones internas y los resultados de la dinámica de las alianzas y conflictos generados a partir de los intentos de su implementación. Lattuada entiende que el análisis del aparato u organización de la administración del Estado resulta insuficiente para dar cuenta de las capacidades estatales, entendidas como las formas de problematizar, priorizar, decidir y gestionar las cuestiones públicas o de agenda del Estado, por lo que es necesario analizar también el desempeño y acciones de los actores o jugadores intervinientes en el proceso de política pública. El autor menciona que la gestión de la política agraria y del desarrollo rural cambió radicalmente en el transcurso del período 2003-2015 con la creación del Ministerio de Agricultura, Ganadería y Pesca (MAGyP), que incorpora una Secretaría de Estado de Desarrollo Rural y Agricultura Familiar en el mismo nivel que la otorgada a la política sectorial, a lo que se sumó la elaboración de un Plan Estratégico Agroalimentario (PEA) con amplia participación social; todos planes y agencias que no lograron institucionalizarse a pesar de la voluntad política de quienes las diagramaron. La gestión de Cambiemos estableció las condiciones para una construcción de institucionalidad diferente, cuya primera innovación consistió en la reconversión del anterior MAGyP en Ministerio de Agroindustria, destacando la importancia de avanzar desde la producción primaria a la de transformación agroalimentaria. Es notorio también el cambio ideológico que propició Macri en cuanto a la agricultura familiar: el sujeto fundamental de las acciones ya no resultaba ser el agricultor familiar, sino que ahora era el "emprendedor" individual.

El segundo capítulo hace hincapié en la política de tierras, entendida como las cuestiones que atañen al dominio, tenencia y uso este recurso estratégico nacional. Aquí Lattuada retoma los aportes de Oszlak y O'Donnell (1976) ya que identifica distintas etapas donde la tierra se constituyó en una "cuestión socialmente problematizada", tema alrededor del cual se han generado tomas de posición desde el Estado y otros actores estratégicos. Las primeras tres etapas son "Tierra y Nación" (fines del siglo XIX, y principios del XX), "Tierra y Equidad Social" (desde el acceso del peronismo al poder), y “Tierra y Productividad" (desde los años '60 a los '90), mientras que la cuarta etapa es identificada como "Tierra y Tecnología", ya que fue gracias al segundo término de la ecuación que se dio un crecimiento significativo y sostenido de la producción agropecuaria, particularmente agrícola, sin que esta dependiera de permanentes incentivos económicos positivos. Luego de los cambios políticos y económicos de 2002, el crecimiento sectorial recobró un nuevo y enérgico impulso de la mano de la inversión, la incorporación de tecnología de punta, el rescate por parte del Estado de las situaciones críticas de endeudamiento, y la consolidación de nuevas formas 
de articulación y redes de organización de la producción. La quinta etapa, que el autor denomina "Tierra y Racionalidad Social", surgió a partir del conflicto "campo-gobierno" de 2008. Así, además de cuestiones irresueltas sobre equidad y rendimiento económico de la tierra, un tema importante en esta nueva problematización del asunto fue el del uso del recurso tierra y su sostenibilidad en el tiempo.

El capítulo tres trata la evolución de las políticas de agricultura familiar en el período en estudio. Frente al imparable proceso de concentración económica que se viene dando en los espacios rurales desde mediados de la década de 1990, la agricultura familiar (la practicada en establecimientos agropecuarios de menos de 500 hectáreas) se vio sumergida, en el período 2003-2015, en un proceso de jerarquización institucional: se reorientaron los fines buscados para el fortalecimiento de sus asociaciones, suscitando que no solo se constituyan en alternativas económicas para enfrentar sus debilidades en el mercado, sino como medio de empoderamiento de estos sectores hasta ahora invisibles en la interlocución con el Estado. Distinta fue la tratativa del gobierno de Mauricio Macri hacia este sector del agro: más vinculado con los sectores agroexportadores concentrados, en su gestión se derivó la cuestión de la pequeña agricultura a una política asistencial que invisibilizaba el rol económico productivo de aquellos sectores que practican la agricultura familiar, a la vez que se identificó este sector con un "bastión del peronismo", quedando así marginado de cualquier avance en políticas públicas. Sin embargo, a pesar de que el discurso macrista y sus políticas apoyaban a los sectores comerciales y agroexportadores, la evolución de estos últimos sectores no fue significativamente mejor, comparada con el período anterior. En este sentido, el autor trata de demostrar que la solución a nivel país en lo que respecta a la concentración económica en el agro no se encuentra en reemplazar el agronegocio por la agricultura familiar, sino en proteger este último tipo de agricultura para que sea capaz de reproducir sus condiciones de sostenibilidad e incorporar nuevas tecnologías, para tener una mejor inserción comercial y una mejor calidad de vida.

En el cuarto capítulo de la obra se analizan en detalle las políticas para el sector agroexportador de granos y carnes. El sector, nos recuerda Lattuada, cumple un triple rol en la economía nacional en tanto generador de divisas, generador de bienes salarios de la población dada su incidencia en los precios de los alimentos, y suministrador de recursos fiscales significativos para el financiamiento del gasto público. En un contexto que a partir de 2005 comenzó a exhibir un aumento sostenido de los precios internacionales de los productos agropecuarios y crecientes tendencias inflacionarias internas, las retenciones selectivas a las exportaciones de productos agropecuarios impulsadas desde el Ministerio de Economía, así como las intervenciones y restricciones en el sistema comercial por la Secretaría de Comercio, se transformaron en los carriles principales a través de los cuales transitó la política para el sector agroexportador, avivando los principales conflictos con los productores de granos y carne. En cambio, la administración macrista tuvo una estrategia 
que priorizaba el mercado externo y la expectativa de atraer inversiones de capitales internacionales promovió durante los primeros años de gobierno el perfil agroexportador del país, sumando a las exportaciones primarias combustibles y energía, hasta que las complicaciones macroeconómicas reclamaron revertir la dirección y realizar un nuevo ajuste sobre estos sectores.

El capítulo quinto evalúa los resultados de las decisiones tomadas por las distintas administraciones expresados en la disponibilidad y acceso a tecnología moderna, el grado de concentración de la estructura productiva, la evolución de la superficie destinada a las diferentes producciones, entre otras cuestiones. Lattuada menciona que la producción agropecuaria argentina tuvo un proceso de crecimiento sostenido desde la década de 1990 hasta la actualidad, producto de una expansión de la frontera agraria a zonas anteriormente marginales y ampliación de superficies de doble cultivo, el incremento de los rendimientos posibilitado por la incorporación de tecnología en insumos (transgénicos, fertilizantes, etc) acceso a equipamiento moderno (grandes maquinarias y agricultura de precisión) y procesos innovadores (siembra directa, organizaciones de pools de siembra y redes productivas). En suma, los resultados en materia de producción y exportaciones agropecuarias fueron menos sensibles a las orientaciones de los diferentes gobiernos y sus políticas que a las dinámicas impuestas por el escenario internacional y a las tendencias de evolución tecnológica y productiva del sector.

El sexto capítulo se encarga de abordar las principales alianzas y conflictos que caracterizaron el período bajo análisis teniendo como eje las políticas implementadas que afectaban al sector rural, exponiendo la diversidad y complejidad de lo que monolíticamente ha sido caracterizado como el conflicto campo-gobierno (una expresión más de la grieta). Una de las manifestaciones visibles de las alianzas que los gobiernos realizan con los diferentes sectores sociales y económicos suele expresarse en la composición de sus gabinetes: los gobiernos kirchneristas incorporaron en sus gabinetes para atender las problemáticas del sector agropecuario a políticos y profesionales (INTA, universidad) identificados con el peronismo y, ocasionalmente, a algún referente local de las entidades gremiales patronales tradicionales del agro (CRA) de comprobada lealtad personal. Una cuestión sonante es que durante el período de 14 años que incluye los gobiernos de Eduardo Duhalde, Néstor y Cristina Kirchner, no hubo presencia presidencial en la centenaria exposición de la Sociedad Rural en el predio de Palermo, a las que Macri asistió puntualmente. Por último, también el gobierno de Macri sumó a los espacios gubernamentales a directores ejecutivos de grandes empresas y representantes reconocidos de las organizaciones gremiales empresarias tradicionales del sector agropecuario (CRA, SRA).

Finalmente, en el apartado de las conclusiones, se procede a una revisión y contrastación de las ideologías y proyectos, con las iniciativas llevadas a cabo y los 
resultados obtenidos, poniendo en crisis los supuestos sostenidos en la construcción de la grieta y advirtiendo sobre la necesidad de revisar y actualizar las ideologías y las alianzas en función de las transformaciones ocurridas en la estructura social y económica argentina de las últimas décadas. En este apartado es notoria una referencia a Obschatko (1988), quien planteara hace décadas que la evolución y competitividad del sector agropecuario argentino no resulta de los incentivos de las políticas neoliberales ni de los intentos de reformas estructurales, sino de su capacidad permanente de innovación e incorporación de tecnología, afirmación desde la cual se plantean los borrosos límites de la grieta en términos de políticas públicas.

El recorrido teórico y analítico, así como el tratamiento que realiza del problema de investigación que encabeza Lattuada, es, a todas luces, novedoso, y constituye un aporte sustantivo en el ámbito de las políticas públicas y de los estudios agrarios, valorable no sólo para los especialistas sino también para el lector preocupado por la realidad del agro argentino. De igual forma, la recuperación de los aportes sobre discurso y política propiciados por Laclau (2005) aportan mayor riqueza al estudio. Finalmente, entendemos que el análisis de políticas públicas sectoriales tiene como principal riqueza, en palabras de Roth Deubel (2010), la de controvertir el papel del Estado y de las instituciones políticas en su definición de la realidad social, para así ofrecer otras lecturas posibles, cuestionando el marco normativo y cognitivo instituido y dominante, tarea que creemos que Lattuada cumple con creces en este trabajo. En definitiva, se trata no de "salvar la grieta" (cosa que significaría anular el conflicto político, fuente de vida de la democracia), sino de pensarla como una cuestión constitutiva de la política argentina y no tanto como una tendencia política estructurante e inexorable, ya que, cuando se va del discurso a la realidad, las políticas, los resultados, los actores y sus alianzas asumieron, al menos para el período 2003-2019, posiciones para nada unívocas.

\section{Referencias bibliográficas}

Roth Deubel, A. N. (Ed). (2010). Enfoques para el análisis de políticas públicas. Bogotá: Universidad Nacional de Colombia. Disponible en: https://shortest.link/ZPR

\section{Bibliografía citada en Lattuada}

Laclau, E. (2005). La Razón Populista, Fondo de Cultura Económica, México.

Obschatko, E. S. de (1988). Las etapas del cambio tecnológico, en Barsky, O. et al. La agricultura pampeana. Transformaciones productivas y sociales. Buenos Aires: Fondo de Cultura Económica, IICA, CISEA.

Oszlak, O., y O' Donnell, G. (1976). Estado y políticas estatales en América Latina: hacia una estrategia de investigación. Documentos CEDES (4). 